\title{
A Masked Two-Coordinate Cobalt(I) Complex That Activates C-F Bonds
}

\author{
Thomas R. Dugan, ${ }^{\dagger}$ Xianru Sun, ${ }^{\neq}$Elena V. Rybak-Akimova, ${ }^{\ddagger}$ Olayinka Olatunji-Ojo, ${ }^{\S}$ Thomas R. Cundari, ${ }^{\S}$ \\ and Patrick L. Holland ${ }^{*+}$
}

${ }^{\dagger}$ Department of Chemistry, University of Rochester, Rochester, New York 14627, United States
${ }^{\ddagger}$ Department of Chemistry, Tufts University, 62 Talbot Avenue, Medford, Massachusetts 02155, United States
${ }^{\S}$ CASCaM, Department of Chemistry, University of North Texas, Denton, Texas 76203, United States

Supporting Information

\begin{abstract}
We report the isolation, characterization, and reactions of the unsaturated complex $\mathrm{L}^{\mathrm{tBu}} \mathrm{Co}\left(\mathrm{L}^{\mathrm{tBu}}=\right.$ bulky $\beta$-diketiminate ligand). The unusual slipped $\kappa N, \eta^{6}$-arene binding mode in $\mathrm{L}^{\mathrm{tBu}} \mathrm{Co}$ interconverts rapidly and reversibly with the traditional $\kappa^{2} N, N^{\prime}$ ligation mode upon binding of Lewis bases, making it a "masked" two-coordinate complex. The mechanism of this isomerization is demonstrated using kinetic studies. $\mathrm{L}^{\mathrm{t} \mathrm{Bu}} \mathrm{Co}$ is a stable yet reactive synthon for low-coordinate cobalt(I) complexes and is capable of cleaving the $\mathrm{C}-\mathrm{F}$ bond in fluorobenzene.
\end{abstract}

$\mathrm{H}$ emilabile ligands, which contain a Lewis basic moiety that can reversibly dissociate from a metal, create transient coordinative unsaturation that can be used for bond activation and catalysis. ${ }^{1}$ Notable examples include catalysts for olefin metathesis and cross-coupling reactions. ${ }^{2}$ In this communication, we report that a bulky $\beta$-diketiminate ligand on cobalt(I) undergoes a novel isomerization that allows it to behave as a hemilabile ligand. Though $\beta$-diketiminates are represented in thousands of metal complexes, ${ }^{3}$ this is the first example of this new binding mode. We show that the ligand isomerization is rapidly reversible and that it provides a "masked two-coordinate" cobalt(I) center for ligand binding and for activation of a strong $\mathrm{C}-\mathrm{F}$ bond.

The addition of tetrahydrofuran (THF) to a solution of $\mathrm{L}^{\mathrm{tBu}} \mathrm{CoNNCoL}^{\mathrm{tBu}}\left[\mathrm{L}^{\mathrm{tBu}}=2,2,6,6\right.$-tetramethyl-3,5-bis $(2,4,6$-triisopropylphenylimido)hept-4-yl $]^{4}$ in $\mathrm{C}_{6} \mathrm{D}_{6}$ gives an immediate color change from brown to dark-green. This color change corresponds to the appearance of a set of signals in the ${ }^{1} \mathrm{H}$ NMR spectrum for a new species, $\mathrm{L}^{\mathrm{tBu}} \mathrm{Co}(\mathrm{THF})(\mathbf{1})$, in quantitative yield. On a preparative scale, 1 can be produced from the reaction of $\mathrm{L}^{\mathrm{tBu}} \mathrm{CoCl}$ with $\mathrm{KC}_{8}$ in THF under $\mathrm{Ar}$, which gives 1 as a dark-green crystalline solid in $64 \%$ yield. Complex 1 (Figure 1 left) has pseudo- $C_{2}$ symmetry in the solid state. The threecoordinate cobalt atom is planar, as the sum of the $\mathrm{N}-\mathrm{Co}-\mathrm{N}$ and $\mathrm{N}-\mathrm{Co}-\mathrm{O}$ bond angles is $359.7(2)^{\circ}$. The THF ligand is bent slightly toward one aryl arm of the $\beta$-diketiminate ligand, with $\mathrm{N}-\mathrm{Co}-\mathrm{O}$ angles of $135.2(1)$ and $125.0(1)^{\circ}$.

A solution of 1 in 5:1 $\mathrm{C}_{6} \mathrm{D}_{6} /$ THF gives an ${ }^{1} \mathrm{H}$ NMR spectrum with nine paramagnetically shifted resonances, indicating $C_{2 v}$ symmetry in solution. Two resonances at $\delta-2.2$ and $-19.6 \mathrm{ppm}$ are absent in THF- $d_{8}$, consistent with rapid exchange of bound THF with solvent. The solution magnetic moment is $3.23(4) \mu_{\mathrm{B}}$ in
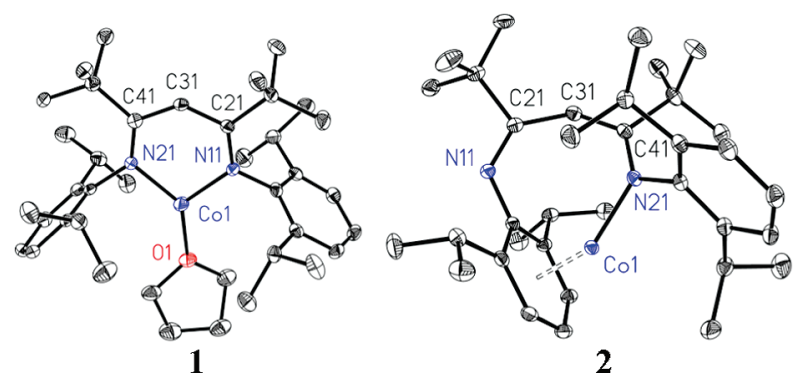

Figure 1. Molecular structures of $\mathrm{L}^{\mathrm{tBu}} \mathrm{Co}(\mathrm{THF})$ (1) and $\mathrm{L}^{\mathrm{tBu}} \mathrm{Co}(2)$ using 50\% probability thermal ellipsoids. $\mathrm{H}$ atoms have been omitted for clarity. Selected bond distances $(\AA)$ and bond angles (deg) for 1: Co1-O1, 2.002(2); Co1-N11, 1.902(3); Co1-N21, 1.881(3); N11Co1-O1, 125.0(1); N21-Co1-O1, 135.2(1); N11-Co1-N21, 99.5(1). For 2: Co1-N21, 1.9037(8); Co1-centroid, 1.61; N11-C21, 1.291(1); C21-C31, 1.464(1); C31-C41, 1.378(1); C41-N21, 1.382(1); N21-Co1-centroid, 148.

THF- $d_{8}$ at $23{ }^{\circ} \mathrm{C}$, corresponding to an $S=1$ ground state; 1 is a high-spin $\mathrm{d}^{8}$ cobalt(I) complex.

Dissolution of 1 in $\mathrm{C}_{6} \mathrm{D}_{6}$ under Ar gives a dark-orange solution whose ${ }^{1} \mathrm{H}$ NMR spectrum shows peaks from 1 plus a number of additional resonances. Evaporation of the volatile materials and redissolution in fresh $\mathrm{C}_{6} \mathrm{D}_{6}$ leads to an ${ }^{1} \mathrm{H}$ NMR spectrum that contains very little 1 . The displacement of THF with aromatic solvents can be used for the synthesis of the unknown species on a gram scale. Thus, $\mathbf{1}$ was dissolved in toluene, and two cycles of solvent removal and addition of more toluene removed all of the THF. Crystallization from a concentrated pentane solution at $-45^{\circ} \mathrm{C}$ under $\mathrm{Ar}$ gave $\mathrm{L}^{\mathrm{tBu}} \mathrm{Co}(2)$ in $72 \%$ yield as brown crystals.

The molecular structure of $\mathbf{2}$ (Figure 1 right) shows a cobalt atom and a single $\beta$-diketiminate ligand with no additional donors. In contrast to the typical $\kappa^{2} N, N^{\prime}$ binding mode for $\mathrm{L}^{\mathrm{tBu}}$, the $\beta$-diketiminate ligand in $\mathbf{2}$ is bound to cobalt in a $\kappa N, \eta^{6}$-arene mode in which the cobalt is bound to the arene ring of an uncoordinated nitrogen atom. The bonds in the NCCCN ring are localized (see the center of Scheme 1 for a valence-bond picture), as evidenced by the alternating bond lengths of 1.291(1), 1.464(1), 1.378(1), and 1.382(1) $\AA$ along the $\beta$-diketiminate backbone. These may be compared with the analogous bond

Received: June 8, 2011

Published: July 19, 2011 

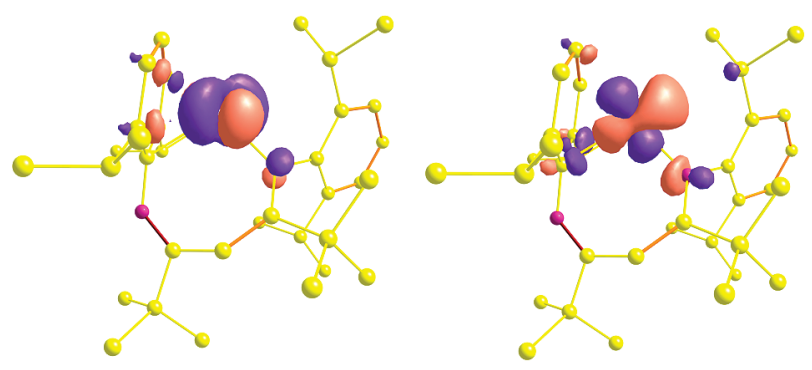

Figure 2. Overlay of the two SOMOs in $\mathbf{2}$ on the DFT-optimized geometry. $\mathrm{H}$ atoms have been omitted for clarity. $\mathrm{C}$, yellow; $\mathrm{N}$, magenta.

Scheme 1. Ligand-Binding Reactions of $\mathrm{L}^{\mathrm{tBu}} \mathrm{Co}$

(2)

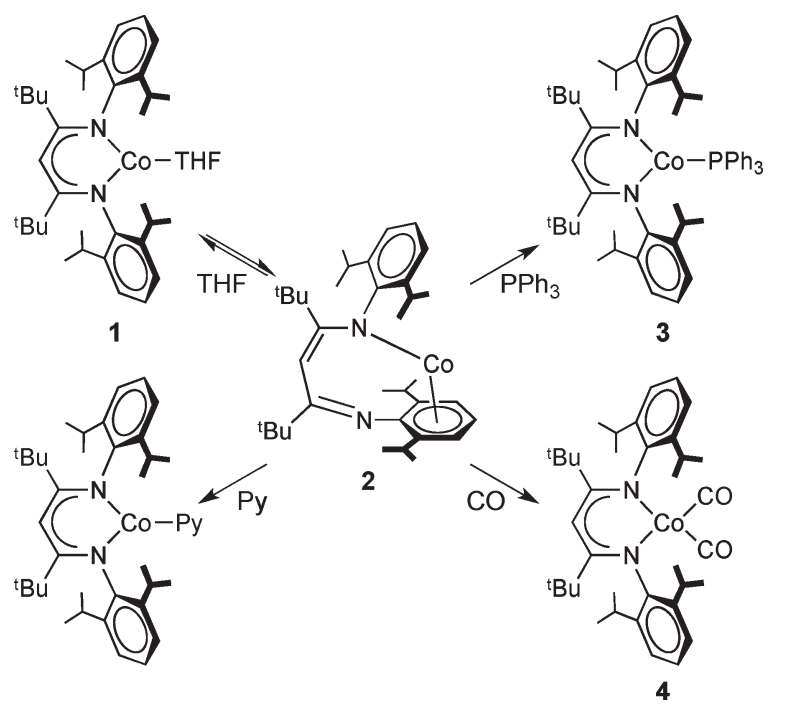

distances of 1.345(4), 1.403(4), 1.402(4), and 1.337(4) $\AA$ in $\mathbf{1}$. The $\beta$-diketiminate backbone deviates only slightly from planarity. The Co-N21 distance of $1.9037(8) \AA$ is similar to the $\mathrm{Co}-\mathrm{N}$ distance in 1 . The $\mathrm{Co}-\mathrm{C}($ arene $)$ bond distances, which range from 2.092 (1) to 2.158(1) $\AA$, are normal. ${ }^{5}$ The $\mathrm{C}-\mathrm{C}$ bond distances in the bound arene are $\sim 0.02 \AA$ longer than in the unbound arene, indicating back-bonding from cobalt(I) into the aromatic ring. The $\mathrm{N} 21-\mathrm{Co}-$ aryl-centroid angle is $148^{\circ}$, making this the first example of an isolated compound with a bent one-legged piano-stool geometry. ${ }^{6}$

The magnetic moment of $\mathbf{2}$ in cyclohexane- $d_{12}$ solution is $3.07(7) \mu_{\mathrm{B}}$ at $27^{\circ} \mathrm{C}$, indicating a high-spin $(S=1)$ electronic configuration. Density functional theory (DFT) calculations (M06 functional and augmented triple- $\zeta$, all-electron basis sets) indicate that the two singly occupied molecular orbitals (SOMOs) are almost entirely metal-based, with small contributions from the ligands (Figure 2). These half-filled orbitals extend lobes toward the open side of the complex. Lower in energy are three doubly occupied Co-based MOs. The electronic structure of $\mathbf{2}$ is thus consistent with a high-spin $\mathrm{d}^{8}$ configuration that is isolobal to triplet $\mathrm{CH}_{2}{ }^{7}$ Though it has the same geometry and number of $\mathrm{d}$ electrons as the highly reactive but unobserved $\mathrm{Cp}^{*} \operatorname{Ir}(\mathrm{L})$ and $\mathrm{Cp}^{*} \mathrm{Rh}(\mathrm{L})(\mathrm{L}=$ phosphine, $\mathrm{CO}$ ) intermediates in $\mathrm{C}-\mathrm{H}$ activation reactions, the heavier analogues are singlets while $\mathbf{2}$ is a triplet, reflecting the small ligand-field splitting of the $3 \mathrm{~d}$ metal. ${ }^{8}$
The ${ }^{1} \mathrm{H}$ NMR spectrum of 2 in cyclohexane- $d_{12}$ indicates $C_{s}$ symmetry in solution, with a mirror plane containing the NCCCN of the $\beta$-diketiminate ligand. The number of peaks in the ${ }^{1} \mathrm{H}$ NMR spectrum of 2 in cyclohexane- $d_{12}$ is invariant between 25 and $80^{\circ} \mathrm{C}$, with no sign of coalescence from trading of coordinated arene rings through a $C_{2 v}$-symmetric intermediate. Therefore, the barrier for isomerization from the $\kappa \mathrm{N}, \eta^{6}$-arene binding mode to the $\kappa^{2} N, N^{\prime}$ mode in $\mathrm{L}^{\mathrm{t} B u} \mathrm{Co}$ is greater than $15 \mathrm{kcal} / \mathrm{mol}$. ${ }^{9}$

The relationship between THF complex $\mathbf{1}$ and rearranged $\mathbf{2}$ is interesting in that dissociation of THF from a 14-electron complex (1) produces a 16-electron complex (2). Intramolecular coordination of ligand aryl groups has been seen in other complexes of bulky ligands and may be reversible ${ }^{10}$ or irreversible. "Masked" coordination has been observed recently in related cobalt(I) and nickel(I) species. ${ }^{12}$ In view of the extensive reorganization of the binding modes of $\mathrm{L}^{\mathrm{tBu}}$ in conversions between $\mathbf{1}$ and $\mathbf{2}$, it is surprising that the conversion of $\mathbf{2}$ to $\mathbf{1}$ takes place in a few seconds upon addition of THF. However, $\mathbf{2}$ and $\mathbf{1}$ are in slow exchange on the NMR time scale, even at $80{ }^{\circ} \mathrm{C}$. Therefore, values of $K_{\text {eq }}$ for binding of THF to 2 to form 1 can be derived from ${ }^{1} \mathrm{H}$ NMR integrations for the two species as a function of [THF].

The equilibrium constants measured at temperatures from 25 to $85{ }^{\circ} \mathrm{C}$ in cyclohexane- $d_{12}$ lead to the thermodynamic parameters $\Delta H^{\circ}=-14.7 \pm 0.5 \mathrm{kcal} / \mathrm{mol}$ and $\Delta S^{\circ}=-40.9 \pm 1.7 \mathrm{eu}$. The equilibrium shifts significantly toward $\mathbf{1}$ at low temperature, and the large negative entropy of reaction is consistent with association of an additional ligand. The binding affinity at room temperature is dependent on the size of the ligand: for THF, $K_{\mathrm{eq}}=$ $19 \pm 5 \mathrm{M}^{-1}$ at $25^{\circ} \mathrm{C}$, whereas for a mixture of cis- and trans-2,5dimethyltetrahydrofuran, $K_{\mathrm{eq}}=0.55 \pm 0.18 \mathrm{M}^{-1}$ at $25^{\circ} \mathrm{C}$.

Compound 2 reacts with $\mathrm{N}_{2}$ to give the previously characterized end-on/end-on bridging dinitrogen complex $\mathrm{L}^{\mathrm{tBu}} \mathrm{CoNNCoL}^{\mathrm{tBu}} \cdot{ }^{4}$ Binding of $\mathrm{N}_{2}$ is relatively weak, as only $95 \%$ conversion is evident in cyclohexane- $d_{12}$ with 1 atm $\mathrm{N}_{2}$. The conversion to $\mathrm{L}^{\mathrm{tBu}} \mathrm{CoNNCoL}^{\mathrm{tBu}}$ is $>95 \%$ when the pressure of $\mathrm{N}_{2}$ is increased to $8 \mathrm{~atm}$. Arenes also bind to 2, although weakly. Addition of benzene to a solution of 2 in cyclohexane- $d_{12}$ results in the appearance of seven new resonances in the ${ }^{1} \mathrm{H}$ NMR spectrum, and the dependence of the integrations on [benzene] gives $K_{\mathrm{eq}}=0.81 \pm 0.26 \mathrm{M}^{-1}$ at $25{ }^{\circ} \mathrm{C}$. The formation of $\mathrm{L}^{\mathrm{tBu}} \mathrm{Co}$ (benzene) also accounts for the extra resonances that are observed in the ${ }^{1} \mathrm{H}$ NMR spectrum of 2 in $\mathrm{C}_{6} \mathrm{D}_{6}$ (see above). The temperature dependence of the equilibrium constant gives $\Delta H^{\circ}=-7.4 \pm 0.3 \mathrm{kcal} / \mathrm{mol}$ and $\Delta S^{\circ}=-28.9 \pm 1.0 \mathrm{eu}$. Similarly, $K_{\text {eq }}=0.65 \pm 0.10 \mathrm{M}^{-1}$ for toluene at $25^{\circ} \mathrm{C}$. The symmetric ${ }^{1} \mathrm{H}$ NMR spectra of $\mathrm{L}^{\mathrm{tBu}} \mathrm{Co}$ (arene) are consistent with $\eta^{6}$ binding, as observed in a close analogue with a smaller diketiminate ligand. ${ }^{13}$ In our system, arenes bind so weakly that the equilibrium concentration of the arene complex is low, and as a result, we cannot rule out lower-hapticity binding modes that exchange rapidly on the NMR time scale.

Compound $\mathbf{2}$ coordinates stronger donors and $\pi$-acidic ligands irreversibly to give new cobalt(I) complexes (Scheme 2). The addition of 1 equiv of $\mathrm{PPh}_{3}$ to a solution of 2 in $\mathrm{C}_{6} \mathrm{D}_{6}$ gives highspin $\mathrm{L}^{\mathrm{tBu}} \mathrm{Co}\left(\mathrm{PPh}_{3}\right)(3)$ (Figure 3 left), which was isolated in $70 \%$ yield. Sparging a solution of 2 in hexane with $\mathrm{CO}$ gas for $5 \mathrm{~min}$ at $20{ }^{\circ} \mathrm{C}$ gives cherry-red $\mathrm{L}^{\mathrm{tBu}} \mathrm{Co}(\mathrm{CO})_{2}(4)$ (Figure 3 right) in $87 \%$ yield. Compound 4 is diamagnetic, as expected for a 16-electron square-planar $\mathrm{Co}^{\mathrm{I}}$ complex. The IR spectrum contains two $\mathrm{C}-\mathrm{O}$ stretching bands at 2014 and $1949 \mathrm{~cm}^{-1}$ that shift to 1970 and $1909 \mathrm{~cm}^{-1}$ when ${ }^{13} \mathrm{CO}$ is used. The ${ }^{13} \mathrm{C}\left\{{ }^{1} \mathrm{H}\right\}$ NMR spectrum of this ${ }^{13} \mathrm{CO}$-labeled sample of 4 shows a singlet for bound $\mathrm{CO}$ at 


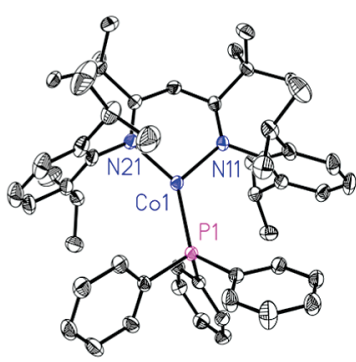

3

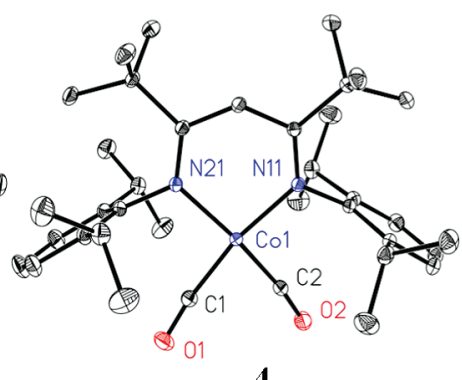

4
Figure 3. Molecular structures of $\mathrm{L}^{\mathrm{tBu}} \mathrm{Co}\left(\mathrm{PPh}_{3}\right)(3)$ and $\mathrm{L}^{\mathrm{tBu}} \mathrm{Co}(\mathrm{CO})_{2}$ (4) using $50 \%$ probability thermal ellipsoids. $\mathrm{H}$ atoms and cocrystallized solvent have been omitted for clarity. Selected bond distances $(\AA)$ and bond angles (deg) for 3: Co1-P1, 2.2176(6); Co1-N11, 1.998(2); Co1-N21, 1.949(2); N11-Co1-P1, 119.52(5); N21-Co1-P1, 142.81(6); N11-Co1-N21, 97.41(7). For 4: Co1-C1, 1.759(1); Co1-C2, 1.753(1); C1-O1, 1.146(1); C2-O2, 1.149(1); Co1-N11, 1.9250(8); Co1-N21, 1.9209(8); Co1-C1-O1, 172.50(9); Co1$\mathrm{C} 2-\mathrm{O} 2, \quad 172.14(9) ; \quad \mathrm{C} 1-\mathrm{Co} 1-\mathrm{C} 2, \quad 81.37(4) ; \quad \mathrm{N} 11-\mathrm{Co} 1-\mathrm{C} 2$, 92.55(4); N21-Co1-C1, 93.62(4); N11-Co1-N21, 94.63(3).

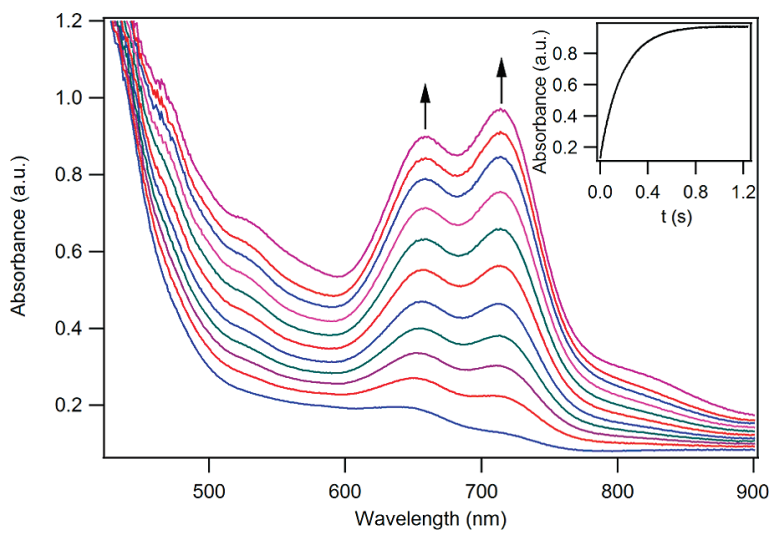

Figure 4. Spectral changes during the reaction of $2(0.3 \mathrm{mM})$ and pyridine $(3.75 \mathrm{mM})$ in hexane at $-40^{\circ} \mathrm{C}$. Inset: time course at $\lambda=715 \mathrm{~nm}$.

$191.24 \mathrm{ppm}$ with a width of $60 \mathrm{~Hz}$; the broadening is attributed to relaxation by quadrupolar ${ }^{59} \mathrm{Co}$.

The addition of 1 equiv of pyridine to a solution of 2 in $\mathrm{C}_{6} \mathrm{D}_{6}$ gives a color change from brown to dark-green. The ${ }^{1} \mathrm{H}$ NMR spectrum shows that $\mathbf{2}$ is quantitatively converted to the threecoordinate pyridine complex $\mathrm{L}^{\mathrm{tBu}} \mathrm{Co}$ (pyridine). ${ }^{14}$ Addition of 1 equiv of 4-tert-butylpyridine or 4-dimethylaminopyridine (DMAP) to 2 yields $\mathrm{L}^{\mathrm{tBu}} \mathrm{Co}$ (tert-butylpyridine) or $\mathrm{L}^{\mathrm{tBu}} \mathrm{Co}-$ (DMAP), respectively. Because of the strong binding of pyridine ligands to 2 and the distinct visible bands in the products, we used these reactions to investigate the mechanism of ligand binding. The rates of binding of pyridine were measured by monitoring the exponential growth of the characteristic metal-to-ligand charge-transfer bands for $\mathrm{L}^{\mathrm{tBu}} \mathrm{Co}$ (pyridine) at $-40{ }^{\circ} \mathrm{C}$ (Figure 4). The spectrum was identical throughout the time course, indicating that no intermediates were present in significant concentrations. The first-order rate constants for pyridine binding increased linearly with pyridine concentration. Thus, the experimental rate law is

$$
-\frac{\mathrm{d}\left[\mathrm{L}^{\mathrm{tBu}} \mathrm{Co}\right]}{\mathrm{d} t}=k\left[\mathrm{~L}^{\mathrm{tBu}} \mathrm{Co}\right][\text { pyridine }]
$$

Scheme 2. Possible Mechanisms for Ligand Binding to $\mathrm{L}^{\mathrm{tBu}} \mathrm{Co}$

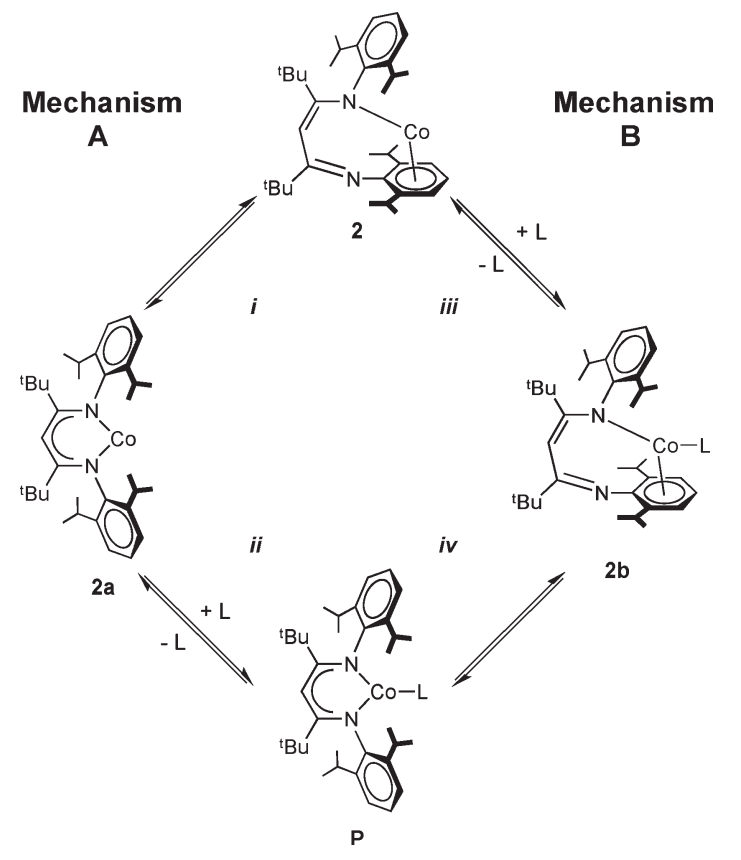

with $k=1.48(3) \times 10^{3} \mathrm{M}^{-1} \mathrm{~s}^{-1}$ at $-40^{\circ} \mathrm{C}$. The rate constant for binding of DMAP is 52 times larger than that for pyridine under identical conditions. The reaction of 2 with THF is at least $10^{5}$ fold slower at $-40{ }^{\circ} \mathrm{C}$. Thus, the rate markedly depends on the concentration and identity of the incoming ligand.

Two possible mechanisms for the $\beta$-diketiminate isomerization process are shown in Scheme 2. Mechanism A starts with step $i$, in which the $\eta^{6}$-arene ligand dissociates from the metal and the imine nitrogen flips to give $\mathbf{2 a}$, a two-coordinate complex wherein the $\beta$-diketiminate binds in the traditional $\kappa^{2} N, N^{\prime}$ geometry. In step $i$, coordination of the added ligand gives the three-coordinate product. In contrast, mechanism B starts with coordination of the second ligand to 2 , forming $2 \mathbf{b}$ (step iii). ${ }^{15}$ In step $i v, \mathbf{2} \mathbf{b}$ then undergoes the arene slip/imine flip isomerization of the $\beta$-diketiminate ligand to form the product.

When the steady-state approximation is used with the reasonable assumption that $k_{i} k_{i i} \gg k_{-i} k_{-i i}$ because of the large overall equilibrium constant, mechanism A predicts a zeroth-order dependence on ligand concentration (see the Supporting Information for the derivation), which does not agree with the rate law obtained using stopped-flow kinetics. Additionally, the rate constant for the reaction of 2 and pyridine at $-40{ }^{\circ} \mathrm{C}$ corresponds to $\Delta G^{\ddagger}=10.1 \mathrm{kcal} / \mathrm{mol}$, while $\Delta G^{\ddagger}$ for the isomerization of 2 to $2 \mathrm{a}$ in step $i$ is at least $15 \mathrm{kcal} / \mathrm{mol}$ (on the basis of the ${ }^{1} \mathrm{H}$ NMR data described above). Therefore, mechanism A is inconsistent with the experimental data. The rate law derived from mechanism B using analogous simplifying assumptions predicts a first-order dependence on both the cobalt and pyridine concentrations. The observed kinetic data are consistent with this prediction and with the rate of ligand binding to 2 being highly dependent on the nucleophilicity and size of the Lewis base. Thus, the evidence most strongly indicates an associative mechanism where coordination of the added ligand precedes $\beta$ diketiminate isomerization. 
Scheme 3. C-F Activation of Fluorobenzene by 2

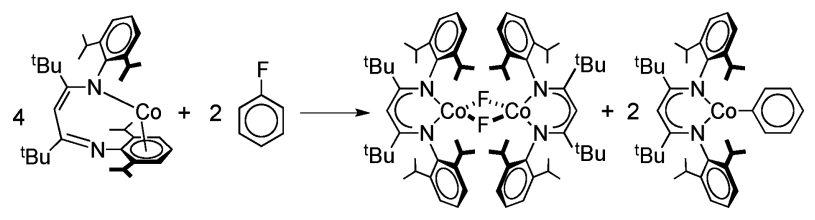

We also explored oxidative addition reactions of 2 . A solution of 2 in cyclohexane- $d_{12}$ does not react with $\mathrm{H}_{2}$ over 1 day, whether $1 \mathrm{~atm} \mathrm{H}_{2} 60{ }^{\circ} \mathrm{C}$ or $10 \mathrm{~atm} \mathrm{H}_{2}$ at $25^{\circ} \mathrm{C}$ is used. The resistance of 2 to oxidative addition reactions is reminiscent of the behavior of other unsaturated cobalt complexes that have a triplet ground state. ${ }^{8,16}$ The addition of fluorobenzene (5 equiv) to a solution of $\mathbf{2}$ in cyclohexane- $d_{12}$ results in the appearance of new set of signals in the ${ }^{1} \mathrm{H}$ NMR spectrum consistent with two new species. Heating to $60{ }^{\circ} \mathrm{C}$ for $18 \mathrm{~h}$ results in complete conversion of $\mathbf{2}$ to the new species. One of the products can be identified as $\mathrm{L}^{\mathrm{tBu}} \mathrm{CoPh}$ on the basis of a comparison to fully characterized $\mathrm{L}^{\mathrm{tBu}} \mathrm{CoPh}$ (synthesized independently using $\mathrm{L}^{\mathrm{tBu}}$ $\mathrm{CoCl}$ and $\mathrm{PhMgCl}) . \mathrm{L}^{\mathrm{tBu}} \mathrm{CoPh}$ accounts for $50 \%$ of the cobalt in the fluorobenzene reaction as determined by integrations. The other product was identified crystallographically as $\left[\mathrm{L}^{\mathrm{tBu}} \mathrm{Co}(\mu\right.$ F) $]_{2} \cdot{ }^{17}$ Accurate integration of its broad, overlapping resonances in the crude ${ }^{1} \mathrm{H}$ NMR spectrum was not possible, so its yield was determined by crystallization, which showed that it accounts for roughly $50 \%$ of the cobalt. These yields point toward the stoichiometry shown in Scheme 3. This is a binuclear oxidative addition, which has been observed for other aryl halides but is rare for the strong $\mathrm{C}-\mathrm{F}$ bond in aryl fluorides. ${ }^{18}$ Therefore, the hemilabile $\beta$-diketiminate ligand in $\mathbf{2}$ can rearrange to the bidentate mode during reductive cleavage of $\mathrm{C}-\mathrm{F}$ bonds in a fluoroarene. The mechanism and scope of $\mathrm{C}-\mathrm{F}$ activation by $\mathbf{2}$ is under study.

In conclusion, the cobalt(I) complex $\mathrm{L}^{\mathrm{tBu}} \mathrm{Co}$ has a $\beta$-diketiminate ligand coordinated in an unprecedented $\kappa N, \eta^{6}$-arene binding mode. Even though our kinetic studies show that a twocoordinate complex is never present, $\mathrm{L}^{\mathrm{tBu}} \mathrm{Co}$ may be termed a "masked two-coordinate complex" because the addition of a variety of different Lewis bases gives three-coordinate complexes in which the $\beta$-diketiminate has undergone rearrangement to the traditional $\kappa^{2} N, N^{\prime}$ binding mode. The use of the masked twocoordinate complex for small-molecule activation has been demonstrated by cleavage of the $\mathrm{C}-\mathrm{F}$ bond in fluorobenzene. Overall, $\mathrm{L}^{\mathrm{tBu}} \mathrm{Co}$ is a versatile compound that shows promise for the development of new cobalt chemistry.

\section{ASSOCIATED CONTENT}

Supporting Information. Details on experiments, computations, and crystallography (CIF). This material is available free of charge via the Internet at http://pubs.acs.org.

\section{AUTHOR INFORMATION}

\section{Corresponding Author}

holland@chem.rochester.edu

\section{ACKNOWLEDGMENT}

We thank Nicole Wedgwood and William Brennessel for crystallographic assistance. Funding was provided by the U.S. Department of Energy, Office of Basic Energy Sciences (Grants
DE-FG02-09ER16089 to P.L.H. and DE-FG02-03ER15387 to T.R.C.) and by the NSF (CHE-0750140, CRIF-0639138, and MRI-0821508 to E.V.R.-A.).

\section{REFERENCES}

(1) (a) Lockwood, M. A.; Fanwick, P. E.; Eisenstein, O.; Rothwell, I. P. J. Am. Chem. Soc. 1996, 118, 2762. (b) Slone, C. S.; Weinberger, D. A.; Mirkin, C. A. Prog. Inorg. Chem. 1999, 48, 233. (c) Braunstein, P.; Naud, F. Angew. Chem., Int. Ed. 2001, 40, 680.

(2) For selected examples, see: (a) Kingsbury, J. S.; Harrity, J. P. A.; Bonitatebus, P. J.; Hoveyda, A. H. J. Am. Chem. Soc. 1999, 121, 791. (b) Nandi, M.; Jin, J.; RajanBabu, T. V. J. Am. Chem. Soc. 1999, 121, 9899. (c) Deckers, P. J. W.; Hessen, B.; Teuben, J. H. Angew. Chem., Int. Ed. 2001, 40, 2516. (d) Weng, Z.; Teo, S.; Hor, T. S. A. Acc. Chem. Res. 2007, 40, 676. (e) Gnanaprakasam, B.; Milstein, D. J. Am. Chem. Soc. 2011, 133,1682 .

(3) Bourget-Merle, L.; Lappert, M. F.; Severn, J. R. Chem. Rev. 2002, 102,3031 .

(4) Ding, K.; Pierpont, A. W.; Brennessel, W. W.; Lukat-Rodgers, G.; Rodgers, K. R.; Cundari, T. R.; Bill, E.; Holland, P. L. J. Am. Chem. Soc. 2009, 131, 9471.

(5) The average Co-C(arene) bond distance of $2.14 \pm 0.04 \AA$ and the average $\mathrm{Co}-$ centroid distance of $1.62 \pm 0.04$ were calculated from $46 \mathrm{Co}-$ arene compounds in the Cambridge Structural Database, version 5.32 (Nov 2010 update) (see: Allen, F. H. Acta Crystallogr. 2002, B58, 380).

(6) Triplet (toluene) $\mathrm{Co}(\operatorname{aryl})$ has a linear one-legged piano-stool geometry. See: Lei, H.; Ellis, B. D.; Ni, C.; Grandjean, F.; Long, G. J.; Power, P. P. Inorg. Chem. 2008, 47, 10205.

(7) Albright, T. A.; Burdett, J. K.; Whangbo, M. H. Orbital Interactions in Chemistry; Wiley: New York, 1985.

(8) (a) Bengali, A. A.; Bergman, R. G.; Moore, C. B. J. Am. Chem. Soc. 1995, 117, 3879. (b) Siegbahn, P. E. M. J. Am. Chem. Soc. 1996, 118, 1487. (c) Snee, P. T.; Payne, C. K.; Kotz, K. T.; Yang, H.; Harris, C. B. J. Am. Chem. Soc. 2001, 123, 2255. (d) Poli, R.; Smith, K. M. Eur. J. Inorg. Chem. 1999, 877.

(9) Thomas, W. A. Annu. Rev. NMR Spectrosc. 1968, 1, 43.

(10) For examples, see: (a) Lentz, M. R.; Vilardo, J. S.; Lockwood, M. A.; Fanwick, P. E.; Rothwell, I. P. Organometallics 2004, 23, 329. (b) Tran, B. L.; Singhal, M.; Park, H.; Lam, O. P.; Pink, M.; Krzystek, J.; Ozarowski, A.; Telser, J.; Meyer, K.; Mindiola, D. J. Angew. Chem., Int. Ed. 2010, 49, 9871.

(11) Bart, S. C.; Hawrelak, E. J.; Lobkovsky, E.; Chirik, P. J. Organometallics 2005, 24, 5518.

(12) (a) Lei, H.; Ellis, B. D.; Ni, C.; Grandjean, F.; Long, G. J.; Power, P. P. Inorg. Chem. 2008, 47, 10205. (b) Ni, C.; Fettinger, J. C.; Long, G. J.; Power, P. P. Inorg. Chem. 2009, 48, 2443. (c) Jones, C.; Schulten, C.; Rose, R. P.; Stasch, A.; Aldridge, S.; Woodul, W. D.; Murray, K. S.; Moubaraki, B.; Brynda, M.; La Macchia, G.; Gagliardi, L. Angew. Chem., Int. Ed. 2009, 48, 7406. (d) Pfirrmann, S.; Yao, S.; Ziemer, B.; Stösser, R.; Driess, M.; Limberg, C. Organometallics 2009, 28, 6855. (e) Ni, C.; Stich, T. A.; Long, G. J.; Power, P. P. Chem. Commun. 2010, 46, 4466. (f) Hung-Low, F.; Bradley, C. A. Organometallics 2011, 30, 2636.

(13) Dai, X.; Kapoor, P.; Warren, T. H. J. Am. Chem. Soc. 2004, 126, 4798.

(14) This compound was characterized previously. See: Ding, K.; Dugan, T. R.; Brennessel, W. W.; Bill, E.; Holland, P. L. Organometallics 2009, 28, 6650.

(15) Though intermediate $\mathbf{2 b}$ is drawn as $\eta^{6}$, the hapticity of the bound arene is only a speculation.

(16) Ingleson, M.; Fan, H.; Pink, M.; Tomaszewski, J.; Caulton, K. G. J. Am. Chem. Soc. 2006, 128, 1804.

(17) This compound has also been synthesized independently. See: Dugan, T. R.; Holland, P. L. Manuscript in preparation.

(18) Zhu, D.; Budzelaar, P. H. M. Organometallics 2010, 29, 5759. 